\title{
(6) OPEN ACCESS \\ The 'diverse, dynamic new world of global tobacco control'? An analysis of participation in the Conference of the Parties to the WHO Framework Convention on Tobacco Control
}

\author{
Evgeniya Plotnikova, Sarah E Hill, Jeff Collin
}

- Additional supplementary files are published online only. To view these files please visit the journal online (http://dx. doi.org/10.1136/ tobaccocontrol-2012-050849)

Global Public Health Unit, University of Edinburgh, Edinburgh, UK

\section{Correspondence to} Professor Jeff Collin, Global Public Health Unit, School of Social and Political Science, University of Edinburgh, 15a George Square, Edinburgh EH8 9LD, UK; jeff.collin@ed.ac.uk

Received 23 October 2012 Accepted 8 November 2012 Published Online First 14 November 2012

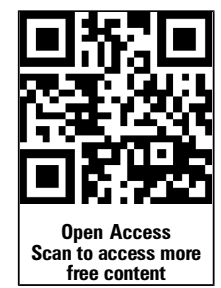

To cite: Plotnikova E, Hill SE, Collin J. Tob Control 2014;23:126-132.

\section{ABSTRACT}

Introduction The increasingly inequitable impacts of tobacco use highlight the importance of ensuring developing countries' ongoing participation in global tobacco control. The WHO Framework Convention on Tobacco Control (FCTC) has been widely regarded as reflecting the high engagement and effective influence of developing countries.

Methods We examined participation in FCTC governance based on records from the first four meetings of the Conference of the Parties (COP), comparing representation and delegate diversity across income levels and WHO regions.

Results While attendance at the COP sessions is high, there are substantial disparities in the relative representation of different income levels and regions, with lower middle and low income countries contributing only $18 \%$ and $10 \%$ of total meeting delegates, respectively. In regional terms, Europe provided the single largest share of delegates at all except the Durban (2008) meeting. Thirty-nine percent of low income countries and $27 \%$ of those from Africa were only ever represented by a single person delegation compared with 10\% for high income countries and $11 \%$ for Europe. Rotation of the COP meeting location outside of Europe is associated with better representation of other regions and a stronger presence of delegates from national ministries of health and focal points for tobacco control.

Conclusions Developing countries face particular barriers to participating in the COP process, and their engagement in global tobacco control is likely to diminish in the absence of specific measures to support their effective participation.

\section{INTRODUCTION}

The rising health impact of tobacco use in developing countries is surely the defining challenge confronting global tobacco control in the 21st century. While annual deaths attributable to tobacco are expected to decline by around 9\% in high income countries (HICs), they are projected to double across low and middle income countries (LMICs) from 3.4 million in 2002 to 6.8 million by $2030 .{ }^{1}$ This rising burden reflects both the global expansion of the tobacco industry ${ }^{2} 3$ and global inequities in tobacco control. ${ }^{4}$ While countries such as South Africa, Thailand and Uruguay are seen as beacons of legislative progress and innovation, ${ }^{45}$ in many developing countries the "implementation of tobacco control measures lags behind the developed world". ${ }^{6}$ In 2010 only an estimated 6\% of the world's population were covered by best practice policies on advertising, with comparable figures for taxation and smoke-free environments of $8 \%$ and $11 \%$, respectively. ${ }^{4}$

Such inequities highlight the need for developing countries to engage effectively in global tobacco control, particularly the work of the WHO Framework Convention on Tobacco Control (FCTC). ${ }^{7}$ Ensuring the ongoing participation of countries with limited resources is crucial in order to realise the full potential of the FCTC beyond negotiation of the Convention itself, in subsequent meetings of the Conference of the Parties (COP) in the protocol on illicit trade.

The literature examining developing country engagement in global governance highlights the multiple obstacles to achieving this. International financial institutions and the World Trade Organisation have been seen as stifling the voice of the Global South and privileging more powerful states. ${ }^{8}$ Negotiations towards environmental agreements are also seen as having effectively disenfranchised many developing countries, ${ }^{9} 10$ and in health the governance processes of global health initiatives to combat infectious diseases have been criticised as marginalising the most vulnerable states. ${ }^{11} 12$

In contrast, accounts of negotiations culminating in the FCTC reported high levels of participation by developing countries and attributed the success of the negotiations to their substantial influence, ${ }^{3} 1314$ while ongoing engagement is suggested by the Convention's remarkably rapid and extensive ratification with 176 countries having become Parties in less than a decade. ${ }^{15}$ An active commitment to promoting developing country participation in FCTC negotiations has been evident in the adoption of a distinctive travel policy for meetings (providing an economy air ticket and per diem expenses for one delegate for all low and lower middle income countries ${ }^{16}$ ) and in rotating the location of COP sessions across WHO regions; while the first COP was held at WHO headquarters in Geneva, Switzerland (in 2006), subsequent meetings were held in Bangkok, Thailand (2007), Durban, South Africa (2008), Punta del Este, Uruguay (2010) and (forthcoming) Seoul, South Korea (2012). ${ }^{17}$

Participant perspectives on the third COP session in Durban vividly depicted the November 2008 meeting as embodying "the diverse, dynamic new world of global tobacco control and health justice". ${ }^{18}$ This depiction has been somewhat qualified by concerns that many LMICs have been 
represented by single person delegations, ${ }^{19}$ thus limiting their ability to participate in concurrent meetings and parallel activities such as drafting groups. More recently, effective participation by developing countries has been further threatened by the adoption of a more restrictive travel policy (limited to "least developed' countries and covering only air tickets), ${ }^{20}$ with the European Union (EU) also indicating a preference for future sessions to be confined to Geneva. ${ }^{21} 22$ Representatives of LMICs and civil society organisations have expressed concern that such changes may compromise the effective engagement of many developing countries in FCTC processes. ${ }^{19}{ }^{23}$

The importance of effective developing country engagement and the political salience of decisions that may affect it suggest the need for a more detailed analysis of representation in global tobacco control. The availability of official lists of participants in COP meetings ${ }^{24-27}$ offers an opportunity to quantify the participation, representation and diversity of participation in COP negotiations. This paper offers an analysis of these documents to consider whether specific income levels (low, lower middle, upper middle and high income countries) and particular regions of WHO have had privileged access to or been marginalised within the FCTC process, to what extent such representation may be affected by meeting location, and which ministries and government agencies have been most active within COP negotiations.

\section{METHODS}

Based on official Secretariat records ${ }^{24-27}$ we compiled lists of those WHO Member States that were Parties to the FCTC and were represented at the first four COP sessions (Geneva 2006, Bangkok 2007, Durban 2008 and Punta del Este 2010), including details of individual delegate members and their institutional affiliations (see online supplementary table 1). (While the EU is classified as a Party to the FCTC we did not include it in our calculations since our unit of analysis was WHO Member States.) We classified all Parties by World Bank income group ${ }^{28}$ and WHO region, ${ }^{29}$ using the most recent categories (see online supplementary tables 2 and 3). Based on 2011 gross national income per capita and using the Atlas method, the World Bank classifies countries as low income (\$1025 or less), lower middle income (\$1026-\$4035), upper middle income (\$4036-\$12 475) or high income (\$12 476 or more). Since this method excludes countries with populations of 30000 or less, a number of small states (Cook Islands, Nauru, Niue and Tuvalu) are not included in these income categories. WHO member states are organised across six regions: the African Region (AFR), Region of the Americas (AMR), South East Asia Region (SEAR), European Region (EUR), Eastern Mediterranean Region (EMR) and Western Pacific Region (WPR).

The resulting dataset was used to calculate the number and proportion of Parties that were present at each COP session, the share of session delegates from each income group and region, the proportion of Parties represented by a single person delegate for each income group and region, and the proportion of session delegates belonging to specific ministries and government agencies. All statistical analyses were carried out by EP using Predictive Analytics SoftWare (PASW Statistics 18.0.0, 2009).

\section{RESULTS}

\section{Participation}

The COP sessions have been broadly characterised by high levels of participation in terms of numbers and proportions of countries present. Ninety-five percent of Parties to the FCTC participated in at least one of the first four sessions, with the proportion of Parties attending each session typically over $80 \%$ across most income groups and regions (table 1). Only a handful of eligible countries did not attend any of the first four COP meetings: these are all small states which ratified the FCTC more recently (Equatorial Guinea, San Marino, Dominica, Belize, Grenada, Gabon, Suriname, Bosnia and Herzegovina, and the Bahamas). A further 23 countries (12\% of WHO member states) who have not yet ratified the FCTC have attended at least one COP session as observers (ie, without rights to vote). ${ }^{30}$

Over time, there has been a decline in attendance at COP meetings as a proportion of all Parties-from 95\% in 2006 to 80\% in 2010. This trend is slightly more pronounced among upper middle and high income countries, with participation falling between 2006 and 2010 from 100\% to 67\% among eligible upper middle income countries and from $92 \%$ to $78 \%$ for HICs.

\section{Representation}

While participation is broadly high in terms of the presence of Parties at COP sessions, different income levels and regions have markedly different representation in terms of their share of the

Table 1 Parties participating in the COP meetings by year and income group/WHO region

\begin{tabular}{|c|c|c|c|c|c|c|c|c|c|c|c|c|c|c|c|c|c|c|c|c|c|c|}
\hline \multirow{3}{*}{$\begin{array}{l}\text { Year (location) of } \\
\text { COP session }\end{array}$} & \multirow{3}{*}{$\begin{array}{l}\text { Parties } \\
\text { present } \\
\text { n }\end{array}$} & \multirow{3}{*}{$\begin{array}{l}\text { Presence as \%* } \\
\text { of all Parties } \\
\%\end{array}$} & \multicolumn{8}{|c|}{ Participating parties by income group $t$} & \multicolumn{12}{|c|}{ Participating parties by WHO region } \\
\hline & & & \multicolumn{2}{|c|}{ Low } & \multicolumn{2}{|c|}{$\begin{array}{l}\text { Lower } \\
\text { middle }\end{array}$} & \multicolumn{2}{|c|}{$\begin{array}{l}\text { Upper } \\
\text { middle }\end{array}$} & \multicolumn{2}{|c|}{ High } & \multicolumn{2}{|c|}{ AFR } & \multicolumn{2}{|c|}{ AMR } & \multicolumn{2}{|c|}{ SEAR } & \multicolumn{2}{|c|}{ EUR } & \multicolumn{2}{|c|}{ EMR } & \multicolumn{2}{|c|}{ WPR } \\
\hline & & & n & $\%$ & n & $\%$ & $\mathrm{n}$ & $\%$ & n & $\%$ & n & $\%$ & n & $\%$ & $n$ & $\%$ & $\mathbf{n}$ & $\%$ & $\mathbf{n}$ & $\%$ & n & $\%$ \\
\hline $\begin{array}{l}\text { COP1: } 2006 \\
\text { (Switzerland) }\end{array}$ & 107 & 95.5 & 14 & 100 & 28 & 93.3 & 27 & 100 & 34 & 91.9 & 20 & 95.2 & 13 & 86.6 & 8 & 88.8 & 29 & 96.6 & 12 & 100 & 25 & 100 \\
\hline COP2: 2007 (Thailand) & 128 & 88.3 & 19 & 95.0 & 40 & 95.2 & 30 & 78.9 & 36 & 87.8 & 27 & 90.0 & 18 & 85.7 & 9 & 90.0 & 32 & 78.0 & 16 & 100 & 26 & 96.3 \\
\hline $\begin{array}{l}\text { COP3: } 2008 \\
\text { (South Africa) }\end{array}$ & 129 & 81.1 & 20 & 83.3 & 36 & 80.0 & 33 & 78.6 & 37 & 84.1 & 32 & 88.8 & 18 & 72.0 & 7 & 70.0 & 33 & 75.0 & 16 & 94.1 & 23 & 85.2 \\
\hline COP4: 2010 (Uruguay) & 136 & 80.0 & 26 & 92.9 & 40 & 85.1 & 31 & 67.4 & 35 & 77.8 & 33 & 80.5 & 20 & 74.1 & 8 & 80.0 & 37 & 80.4 & 15 & 78.9 & 23 & 85.2 \\
\hline $\begin{array}{l}\text { Parties attending any } \\
\text { COP session 2006-2010 }\end{array}$ & 161 & 94.7 & 28 & 100 & 46 & 97.9 & 42 & 91.3 & 41 & 91.1 & 39 & 95.1 & 22 & 81.5 & 10 & 100 & 44 & 95.7 & 19 & 100 & 27 & 100 \\
\hline
\end{tabular}

*Based on Member States that were Parties to the Framework Convention on Tobacco Control on the final day of the relevant COP session. ${ }^{15}$

tWorld Bank income categories exclude a number of small states (including the Cook Islands, Nauru, Niue and Tuvalu) which are therefore not included in these subtotals or in calculating percentage participation by income group. For this reason the sum of participating Parties in each income category is less than the total number of participating Parties in the relevant COP session.

AFR, African Region; AMR, Region of the Americas; COP, Conference of the Parties; EMR, Eastern Mediterranean Region; EUR, European Region; SEAR, South East Asia Region; WPR, Western Pacific Region. 
Table 2 Delegate share by year and income group

\begin{tabular}{|c|c|c|c|c|c|c|c|c|c|}
\hline \multirow[b]{2}{*}{ Year (location) of COP session } & \multirow[b]{2}{*}{ Total delegates at meeting } & \multicolumn{8}{|c|}{ Proportion of delegates from each income group* } \\
\hline & & Low & & Lower r & dle & Upper $r$ & dle & High & \\
\hline COP1: 2006 (Switzerland) & 474 & $8.1 \%$ & & $18.1 \%$ & & $28.8 \%$ & & $45.0 \%$ & \\
\hline COP2: 2007 (Thailand) & 396 & $8.7 \%$ & $(9.7 \%)$ & $15.6 \%$ & $(17.5 \%)$ & $39.3 \%$ & $(31.8 \%)$ & $36.5 \%$ & $(41.0 \%)$ \\
\hline COP3: 2008 (South Africa) & 412 & $9.6 \%$ & $(11.0 \%)$ & $18.1 \%$ & $(20.8 \%)$ & $40.9 \%$ & $(32.1 \%)$ & $31.4 \%$ & $(36.1 \%)$ \\
\hline COP4: 2010 (Uruguay) & 457 & $12.0 \%$ & $(12.8 \%)$ & $20.7 \%$ & $(21.9 \%)$ & $39.1 \%$ & $(35.4 \%)$ & $28.2 \%$ & $(29.9 \%)$ \\
\hline Average across COP1-COP4 & 435 & $9.6 \%$ & $(10.4 \%)$ & $18.1 \%$ & $(19.6 \%)$ & $37.0 \%$ & $(32.0 \%)$ & $35.3 \%$ & $(38.0 \%)$ \\
\hline
\end{tabular}

total delegates at each COP. Sessions tended to be numerically dominated by delegations from HICs and regionally from within WHO Europe (tables 2 and 3), although there is some variation in this pattern according to the location of the meeting. Similarly, low and lower middle income countries and those from outside Europe were more likely to be represented by a single person delegation (tables 4 and 5).

In terms of delegate numbers, there is a tendency for higher income Parties to be over-represented at the COP sessions, while low and lower middle income countries provide a much smaller share of delegates at each session (table 2). This gradient was most marked at the first session in Geneva, at which $45 \%$ of all delegates came from HICs (comprising 34\% of all Parties) compared with just $8 \%$ from low income countries $(13 \%$ of all Parties). Representation of upper middle income countries improved in subsequent sessions (COP2-4), all of which were held in upper middle income countries; this effect is somewhat attenuated if delegates from the host country are excluded, but upper middle income countries still retain a delegate share comparable to that of HICs. In contrast, low and lower middle income countries have limited numerical representation across all four COP sessions with average delegation shares of $10 \%$ and $18 \%$, respectively (whereas these income groups comprised $17 \%$ and $28 \%$ of all Parties).

In regional terms, Europe has shown a marked numerical dominance at COP sessions, particularly COP1 in Geneva (table 3) at which almost $40 \%$ of the delegates were European (whereas European countries constituted only 27\% of all Parties at this time). Even for meetings outside Europe, the EUR provided the largest single cohort of delegates for all except COP3 (2008) at which it was still the largest region when host country delegates are excluded. In contrast, the EMR provided the smallest share of delegates at all meetings; this partly mirrors the relatively small share of Parties from this region (11\%) but may also reflect the concurrence of some meetings with important religious events. ${ }^{23}$
There is evidence that regional representation improves in line with the location of the COP sessions, with meetings in Thailand, South Africa and Uruguay providing the largest delegate presence from South East Asia (15\%), Africa (33\%) and the Americas (24\%), respectively. This effect is partly attenuated once host country delegates are excluded from these figures-most notably for COP2 in Bangkok, although the effect of regional boundaries should be borne in mind here. There is some evidence of spill-over benefits in terms of representation from neighbouring regions, particularly in relation to COP2: if delegates from the host country are excluded, the WPR had its largest delegate presence at this meeting.

Representation by a single person delegation was much more common for poorer countries (table 4). Almost 40\% of low income countries were only ever represented by a single person delegation, and a large majority of both low and lower middle income countries ( $86 \%$ and $78 \%$, respectively) were represented by a single person delegation for at least one of the first four COP sessions. In contrast, among HICs only $10 \%$ were only ever represented by a single person delegation, and a minority (39\%) were represented by a single person delegation at any of the first four meetings. Single person representation also varied by WHO region (table 5). The WPR (including many small island nations) had a particularly high proportion of single person delegations, while over a quarter of countries from the AFR and EMR were only ever represented by a single person delegation during the first four COP sessions.

\section{Diversity}

The composition of delegations showed substantial variation in the expertise and institutional affiliation of delegate members, both by income categories and across the four meetings. Delegations from low income countries drew more heavily on officials from ministries of health and from national focal points for tobacco control, which in combination account for almost three-quarters of all low income delegates (figure 1).

Table 3 Delegate share by year and WHO region

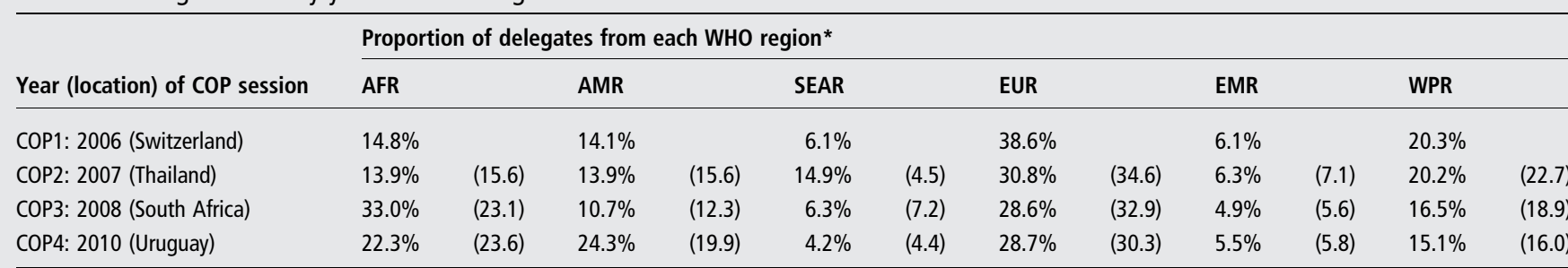

${ }^{*}$ Figures in parentheses give proportions for each meeting after excluding the host country.

AFR, African Region; AMR, Region of the Americas; COP, Conference of the Parties; EMR, Eastern Mediterranean Region; EUR, European Region; SEAR, South East Asia Region; WPR, Western Pacific Region. 
Table 4 Countries (number and proportion*) represented by a single person delegation at the first four COP meetings (2006-2010), by income group

\begin{tabular}{|c|c|c|c|c|c|c|c|c|c|c|}
\hline \multirow[b]{2}{*}{ Represented by a single person delegation } & \multicolumn{2}{|c|}{$\begin{array}{l}\text { All income } \\
\text { groupst }\end{array}$} & \multicolumn{2}{|c|}{ Low } & \multicolumn{2}{|c|}{ Lower middle } & \multicolumn{2}{|c|}{ Upper middle } & \multicolumn{2}{|c|}{ High } \\
\hline & n & $\%$ & n & $\%$ & n & $\%$ & n & $\%$ & $\mathbf{n}$ & $\%$ \\
\hline Always & 33 & 21.0 & 11 & 39.3 & 13 & 28.3 & 5 & 11.9 & 4 & 9.8 \\
\hline Sometimes & 69 & 43.9 & 13 & 46.4 & 23 & 50.0 & 21 & 50.0 & 12 & 29.3 \\
\hline Never & 55 & 35.0 & 4 & 14.3 & 10 & 21.7 & 16 & 38.1 & 25 & 61.0 \\
\hline
\end{tabular}

*Proportion given as a percentage of countries participating in the COP, by income.

tExcludes countries not included in World Bank income classification (of which three were always represented by a single person delegation, and four were represented by a single person delegation at least once).

COP, Conference of the Parties.

By contrast, among HIC delegations attending the first four COP sessions representatives from ministries of health and national focal points were outnumbered by those from foreign affairs, diplomatic missions and finance ministries.

The institutional affiliation of delegation members also showed variation across the four COP meetings. COP1 (in Geneva) was dominated by members of national diplomatic missions, while delegates from national focal points for tobacco control became much more prominent in subsequent meetings (figure 2). Representatives of national ministries of agriculture and trade or commerce had a stronger presence at COP4 in Uruguay.

\section{DISCUSSION}

In broad terms, our analysis presents a qualified success story in terms of the high attendance at COP sessions across all regions and income categories. The caveat to this success is the slight decline in the proportion of Parties attending more recent COP meetings, possibly reflecting a decline in the political priority afforded to tobacco control in the context of the global financial crisis. The story becomes more complex when comparative representation by income category and by region is considered, with lower income countries and those from outside Europe shown to have a smaller share of delegates at the first four COP sessions. These inequities in representation suggest that, despite its reputation for active participation by developing countries, ${ }^{3} 1314$ the FCTC's governing body is affected by the same geopolitical and economic obstacles that curtail developing countries' representation in other areas of global governance. $^{8-10} 12$

Several indicators suggest that poorer countries face particular barriers to achieving effective participation. Low and lower middle income countries provide a substantially smaller proportion of COP delegates than high and upper middle income countries, and are also far more likely to be represented by a single person delegation. Institutionally, low income delegations seem to be characterised by a strongly health-oriented perspective, although the development of multi-sectoral approaches to tobacco control might be seen as hindered by the low levels of participation from key ministries including finance. A number of indicators also point to a significant regional bias in COP representation: countries from the AFR, WPR and EMR are more likely to be represented by a single person delegation, while numerically the EUR has dominated every COP meeting except that in Durban (2008) - a dominance further exacerbated by the presence of a sizeable EU delegation (not included in our analyses). Since the COP is the forum via which FCTC decision making occurs, ${ }^{21}$ the relatively weaker representation of developing countries in this context highlights the challenge of achieving equitable participation in global health governance.

Yet there are also encouraging indications that policies adopted to promote developing country participation in the FCTC have mitigated the effect of structural inequalities in global economic and geopolitical processes. Arrangements for travel funding and the practice of rotating COP meeting locations outside of Europe have served to increase participation by delegates from low and lower middle income countries and to improve representation from other regions. Sessions held outside Geneva have also been associated with stronger representation from national ministries of health and focal centres for tobacco control rather than diplomatic missions.

In this context, the decision at COP4 to reduce travel support ${ }^{20}$ and the strong preference of the EUR to hold future negotiations in Geneva ${ }^{23}$ both raise significant concerns for the future character of COP negotiations. The decision to curtail funding for travel support emerges here as profoundly misguided from a global health perspective. Discussions during COP4 were characterised by the starkest of dividing lines between wealthier countries speaking in support of reduced provision (EU, Canada, Norway and Japan) and countries from the Global South opposing the reduced participation seen as its

Table 5 Countries (number and proportion*) represented by a single person delegation at the first four COP meetings (2006-2010), by WHO region

\begin{tabular}{|c|c|c|c|c|c|c|c|c|c|c|c|c|c|c|}
\hline \multirow[b]{2}{*}{ Represented by a single person delegation } & \multicolumn{2}{|c|}{ All regions } & \multicolumn{2}{|c|}{ AFR } & \multicolumn{2}{|c|}{ AMR } & \multicolumn{2}{|c|}{$\underline{\text { SEAR }}$} & \multicolumn{2}{|c|}{ EUR } & \multicolumn{2}{|c|}{ EMR } & \multicolumn{2}{|c|}{ WPR } \\
\hline & n & $\%$ & n & $\%$ & n & $\%$ & n & $\%$ & n & $\%$ & n & $\%$ & n & $\%$ \\
\hline Always & 36 & 22.4 & 11 & 28.2 & 5 & 22.7 & 2 & 20.0 & 5 & 11.4 & 5 & 26.3 & 8 & 29.6 \\
\hline Sometimes & 70 & 43.5 & 17 & 43.6 & 11 & 50.0 & 4 & 40.0 & 17 & 38.6 & 10 & 52.6 & 11 & 40.7 \\
\hline Never & 55 & 34.2 & 11 & 28.2 & 6 & 27.3 & 4 & 40.0 & 22 & 50.0 & 4 & 21.1 & 16 & 59.3 \\
\hline
\end{tabular}

*Proportion given as a percentage of countries participating in the COP, by region.

AFR, African Region; AMR, Region of the Americas; COP, Conference of the Parties; EMR, Eastern Mediterranean Region; EUR, European Region; SEAR, South East Asia Region; WPR, Western Pacific Region. 
Figure 1 Institutional affiliation of national delegates attending Conference of the Parties meetings (2006-2010) from low and high income countries. Finance, Ministry of Finance or equivalent; Foreign Affairs, Ministries of Foreign Affairs or diplomatic missions; Health, Ministry of Health or equivalent; Other, all other institutional categories including industry and trade, agriculture, justice and all other government departments; TC focal point, national focal point for tobacco control.

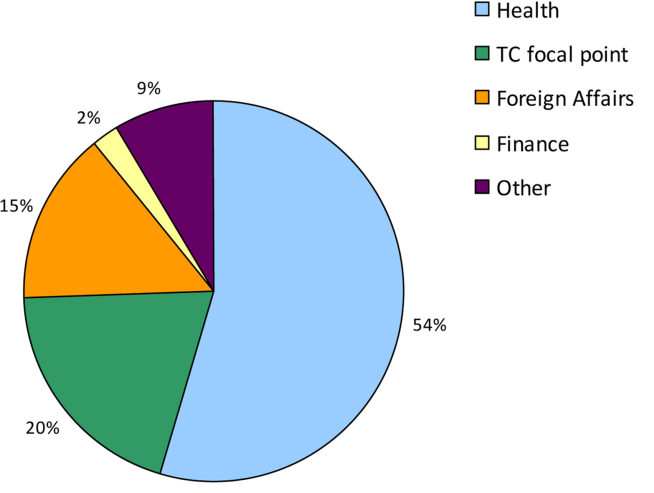

Low income countries

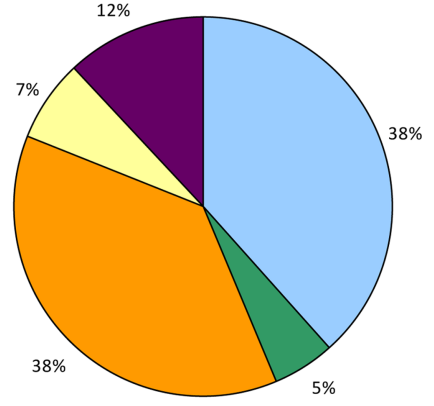

High income countries

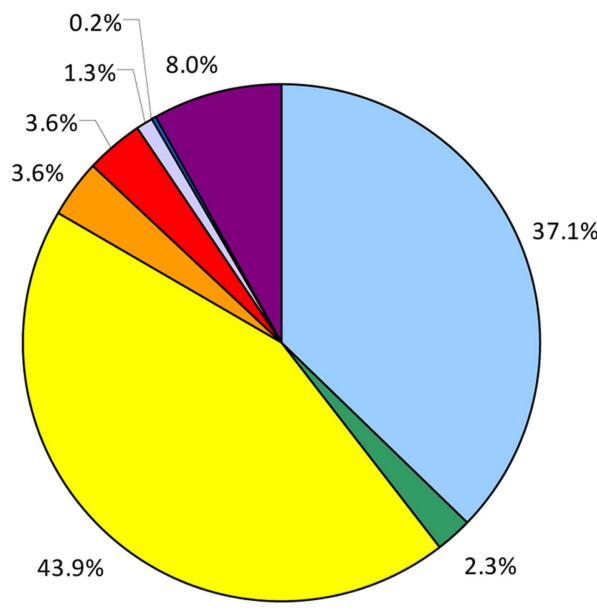

Switzerland (2006) $\square$ Health

$\square$ TC focal point

$\square$ Diplomatic Mission

$\square$ Foreign Affairs

$\square$ Finance

$\square$ Agriculture

$\square$ Trade / Commerce

other

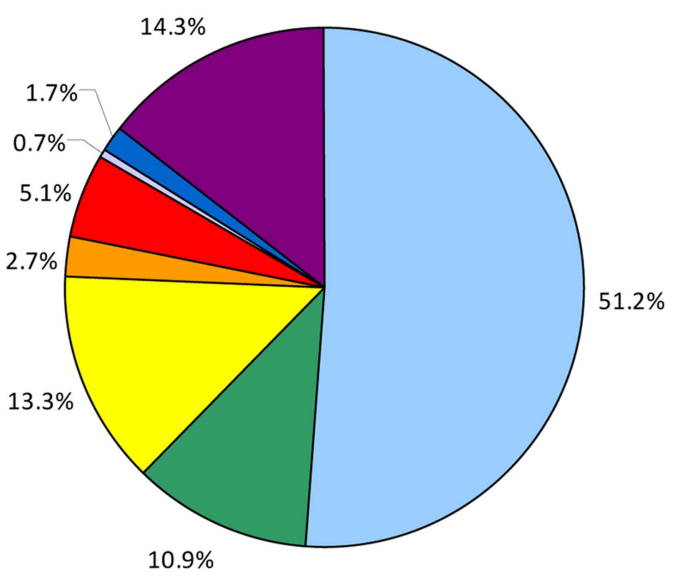

South Africa (2008)

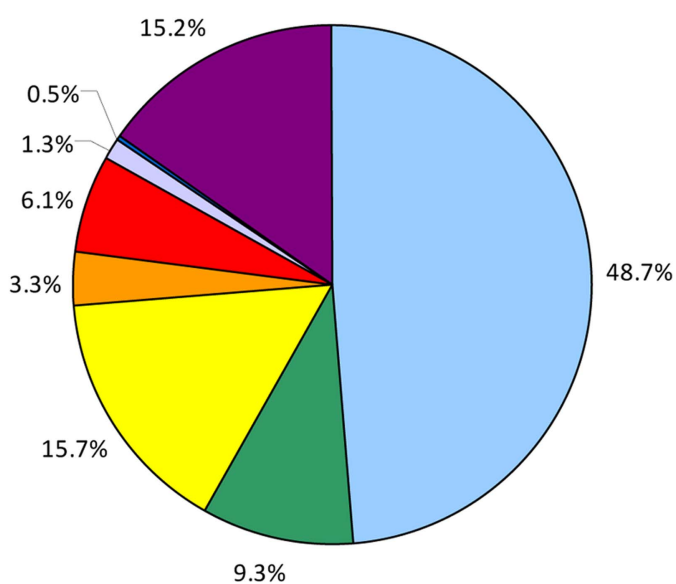

Thailand (2007)

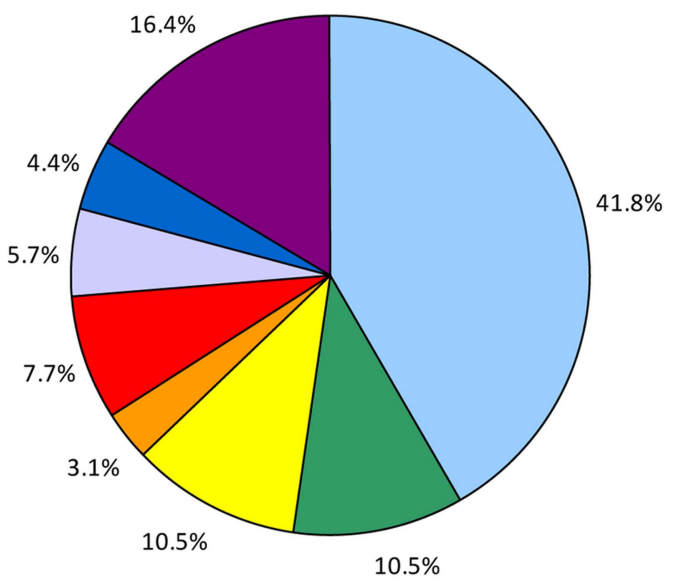

Uruguay (2010)

Figure 2 Institutional affiliation of national delegates attending Conference of the Parties meetings (2006-2010) by meeting location*. Agriculture, Ministry of Agriculture or equivalent; Diplomatic Mission, diplomatic mission to Geneva; Finance, Ministry of Finance or equivalent; Foreign Affairs, Ministries of Foreign Affairs or equivalent; Health, Ministry of Health or equivalent; Other, all other institutional categories and government departments; TC focal point, national focal point for tobacco control; Trade/Commerce, Ministries of Trade, Commerce or equivalent. ${ }^{*}$ Figures apply only to delegates from countries eligible to vote at the relevant meeting. 
inevitable consequence. ${ }^{23}$ In addition to reflecting a clear assertion of self-interest, arguments to reduce funding support rested on a distinction between supporting participation in the FCTC and core tobacco control activities. We concur with the delegate from Brazil in failing to understand "the logic of the argument... that lower participation would result in better implementation of the Convention". ${ }^{22}$ While the temptation to reduce travel costs in the context of financial crisis is understandable, the sums involved appear negligible given the staggering disjuncture between tobacco's contribution to global mortality and the tiny proportion of health-related development assistance devoted to tobacco control, some $0.09 \%$ for $2007 .^{31}$

Geneva does have some benefits as a location for key FCTC meetings. Across the four COP sessions, none of the WHO regions had their lowest share of delegates at the Geneva meeting, which also had the smallest number and proportion of single person delegations. Holding such meetings in Geneva also provides access to the broad expertise and skills of diplomatic missions. Such advantages are, in our view, substantially outweighed by problems associated with a fixed Geneva location, particularly in the context of reduced availability of travel funds for developing countries. On the basis of the data presented above, such decisions could be expected to result in inter alia a renewal of the numerical dominance of European delegations, a reversal of the substantial improvements made in participation by low and lower middle income countries and the AFR region, and a dilution of the health-oriented character of COP negotiations. More broadly, such changes threaten to replicate the bias in favour of HICs that is widely seen as characterising global governance, ${ }^{8-12}$ but that to date the WHO and Parties to the FCTC have assiduously and in many respects effectively worked to avoid. In addition, holding COP sessions in Geneva might arguably be seen as inappropriate given that Switzerland has not yet ratified the FCTC.

\section{Limitations}

Our analysis has some limitations, most importantly in its reliance on official records of COP attendees which list delegates put forward by Parties but do not indicate their level of participation. Thus our analysis cannot address the quality of delegate participation, and figures for some meetings may be inflated by the inclusion of delegate members whose involvement was nominal (this is likely to be most pronounced for the 2006 Geneva session, where members of local diplomatic missions may have attended only briefly). By grouping delegates into broad institutional categories (based on non-standard information in attendance lists) it is also possible that we have misclassified some delegates. Classification of countries by income and region was based on the most recent World Bank and WHO groups so will not take account of any changes in categorisation of countries that may have occurred between 2006 and 2012; such changes are likely to be marginal, however, and we judged it preferable to be consistent in categorising individual countries across the four COP sessions. The exclusion of four small states from World Bank income categories mean Parties within the four income categories add up to less than the total number of Parties participating in each meeting, and mean our results for low and lower middle income categories may differ slightly from those based on other methods. ${ }^{32}$

\section{Conclusions}

The first four meetings of the COP to the FCTC were characterised by high attendance across all regions and income categories but notable inequities in relative delegation size, with lower income countries and those outside the EUR comparatively under-represented in terms of delegate share. There is also some evidence that these countries may struggle to include key areas of expertise (such as finance) in their delegations. These findings indicate that, despite its reputation for high levels of developing country participation, the FCTC is affected by the same geopolitical and economic obstacles that bias representation in other areas of global governance.

The issues of participation, representation and diversity with which this paper engages may seem rather abstract, but such concerns are central to the capacity of Parties to fulfil the objectives of the FCTC. Effective participation in the FCTC can be viewed as central to promoting the implementation of its measures, and the inequities outlined above have implications for the process and content of COP decision making. The limitations of single person delegations, for example, are vividly demonstrated by the absence from the committee room of many developing countries when the draft decision on travel funding was circulated during COP4, since they could not attend concurrent meetings. ${ }^{23}$

Promoting the globalisation of effective tobacco control interventions across developing countries can reasonably be regarded as both the FCTC's principal task and also its greatest challenge. To date, the active participation of developing countries in the FCTC has been regarded as both an indicator and a cause of its success. It is greatly to be hoped that forthcoming discussions at COP5 in Seoul do not undermine the collective capacity of the Parties to address this challenge in the future.

\section{What this paper adds}

- The WHO Framework Convention on Tobacco Control (FCTC) is the principal means of addressing the shifting global burden of tobacco-attributed mortality and requires the active engagement of developing countries.

- Developing countries are often marginalised and under-represented within global governance processes, although observer accounts of FCTC negotiations depict a high level of developing country engagement and influence.

- While meetings of the Conference of Parties (COP) to the FCTC have been characterised by high levels of participation, they have been numerically dominated by delegates from high and upper middle income countries and from WHO Europe.

- Low and lower middle income countries and those from Africa are much more likely to be represented by single person delegations, thus limiting their capacity to participate in key discussions.

- The distinctive travel policy adopted during FCTC negotiations and the practice of rotating the venues of COP meetings have been associated with more diverse representation.

- Measures to support the effective participation of developing countries in the FCTC are of central importance to global tobacco control.

Correction notice This article has been corrected since it was published Online First. The grant number listed in the Funding section has been corrected from '2 R01 CA091021-05' to 'R01 CA160695-01'.

Acknowledgements We are grateful to three anonymous reviewers and to Yvona Tous and Paul Norris for comments on earlier versions of this paper.

Contributors JC developed the initial concept for the paper; EP and SEH developed and undertook the data analysis; EP wrote the first draft. EP, SEH and JC 
contributed to the writing of the manuscript and agree with its results and conclusions.

Funding This research is supported by the National Cancer Institute of the US National Institutes of Health (grant number R01 CA160695-01).

\section{Competing interests None.}

Provenance and peer review Not commissioned; externally peer reviewed.

Data sharing statement Data were derived from official lists of participants in COP meetings (available publicly via the WHO website).

Open Access This is an Open Access article distributed in accordance with the Creative Commons Attribution Non Commercial (CC BY-NC 3.0) license, which permits others to distribute, remix, adapt, build upon this work non-commercially, and license their derivative works on different terms, provided the original work is properly cited and the use is non-commercial. See: http://creativecommons.org/licenses/by-nc/3.0/

\section{REFERENCES}

1 Mathers $C D$, Loncar $D$. Projections of global mortality and burden of disease from 2002 to 2030. PLoS Med 2006:3:e442.

2 Yach $D$, Bettcher $D$. Globalisation of tobacco industry influence and new global responses. Tob Control 2000:9:206-16.

3 Collin J, Lee K. Globalization and the politics of health governance: the framework convention on tobacco control. In: Cooper A, Kirton J eds. Innovation in global health governance: critical cases. Farnham: Ashgate, 2009:219-41.

4 WHO. WHO report on the global tobacco epidemic, 2011: warning about the dangers of tobacco. Geneva: World Health Organization, 2011.

5 de Beyer J, Brigden LW. Tobacco control policy: strategies, successes, and setbacks. Washington, DC/Ottawa: World Bank/The International Development Research Centre, 2003.

6 David A, Esson K, Perucic A-M, et al. Tobacco use: equity and social determinants. In: Blas E, Kurup AS eds. Equity, social determinants and public health programmes. Geneva: World Health Organization, 2010:199-217.

7 WHO. Framework convention on tobacco control. Geneva: World Health Organization, 2003.

8 Glenn J. Global governance and the democratic deficit: stifling the voice of the south. Third World Q 2008;29:217-38.

9 Fisher D, Green J. Understanding disenfranchisement: civil society and developing countries' influence and participation in global governance for sustainable development. Global Environ Polit 2004:4:65-84.

10 McGregor I. Disenfranchisement of countries and civil society at COP-15 in Copenhagen. Global Environ Polit 2010:11:1-7.

11 Buse K, Harmer A. Power to the partners?: the politics of public-private health partnerships. Development 2004:47:49-56.

12 Buse K, Harmer A. Seven habits of highly effective global public-private health partnerships: practice and potential. Soc Sci Med 2007:64:259-71.

13 Hammond R, Assunta M. The framework convention on tobacco control: promising start, uncertain future. Tob Control 2003;12:241-2.

14 Wilkenfeld J. Saving the world from big tobacco: the real coalition of the willing. Pittsburg: Ridgway Center, 2005.

15 WHO. Parties to the WHO Framework Convention on Tobacco Control. 2012 http://www.who.int/fctc/signatories_parties/en/index.html (accessed 23 Oct 2012).
16 WHO. Travel support available to Parties to the WHO FCTC. 24 July 2012, FCTC/COP/5/22 WHO Framework Convention on Tobacco Control Convention Secretariat; 2012, Report by the Secretariat.

17 WHO. Sessions of the Conference of the Parties to the WHO FCTC. 2012. http://www.who.int/fctc/cop/sessions/en/ (accessed 23 Oct 2012).

18 Malone R. From the editor: the diverse, dynamic new world of global tobacco control. Tob Control 2009:18:75.

19 Framework Convention Alliance. Governments' participation in global tobacco control efforts threatened. 2012. (cited 16 Oct 2012). http://www.fctc.org/index php?option=com_content\&view=article\&id $=809$ : governments-participation-in-global-tobacco-control-efforts-threatened\&catid=275: fctc-action-now-fctc-processes\&ltemid=503 (accessed 23 Oct 2012).

20 WHO. Harmonization of travel support available to parties to the WHO framework convention on tobacco control. 20 November 2010 FCTC/COP4(21). Geneva: WHO Framework Convention on Tobacco Control Convention Secretariat, 2010.

21 Liberman J. Four COPs and counting: achievements, underachievements and looming challenges in the early life of the WHO FCTC conference of the Parties. Tob Control 2012:21:215-20.

22 WHO. Conference of the Parties to the WHO Framework Convention on Tobacco Control, Fourth Session, Punta del Este, Uruguay, 15-20 November 2010: Summary Records of Committees. FCTC/COP/4/REC/3. Geneva: WHO Framework Convention on Tobacco Control Convention Secretariat, 2010.

23 WHO. Conference of the Parties to the WHO Framework Convention on Tobacco Control, Fourth Session, Punta del Este, Uruguay, 15-20 November 2010: Verbatim Records of Plenary Meetings. FCTC/COP/4/REC/2. Geneva: WHO Framework Convention on Tobacco Control Convention Secretariat, 2011.

24 WHO. Conference of the Parties to the WHO Framework Convention on Tobacco Control, First Session, Geneva, 6-17 February 2006: Decisions and Ancillary Documents. COP/1/2006/CD. Geneva: WHO Framework Convention on Tobacco Control Convention Secretariat, 2006.

25 WHO. Conference of the Parties to the WHO Framework Convention on Tobacco Control, Second Session, Bangkok, 30 June-6 July 2007: Decisions and Ancillary Documents. COP/2/2007/CD. Geneva: WHO Framework Convention on Tobacco Control Convention Secretariat, 2007.

26 WHO. Conference of the Parties to the WHO Framework Convention on Tobacco Control, Third Session, Durban, South Africa, 17-22 November 2008: Decisions and Ancillary Documents. FCTC/COP/3/REC/1. Geneva: WHO Framework Convention on Tobacco Control Convention Secretariat, 2008.

27 WHO. Conference of the Parties to the WHO Framework Convention on Tobacco Control, Fourth Session, Punta del Este, Uruguay, 15-20 November 2010: Decisions and Ancillary Documents. FCTC/COP/4/REC/1. Geneva: WHO Framework Convention on Tobacco Control Convention Secretariat, 2010.

28 World Bank. How we classify countries. 2012. http://data.worldbank.org/about/ country-Classifications (accessed 23 Oct 2012).

29 WHO. World health statistics 2012. Geneva: World Health Organization, 2012.

30 WHO. Rules and procedure of the conference of the parties to the wHO framework convention on tobacco control, part 9, rule 29. Geneva: World Health Organization, 2006.

31 Ross H, Stoklosa M. Development assistance for global tobacco control. Tob Control 2012;21:465-70

32 WHO. Travel support available to parties to the WHO FCTC: report by the secretariat. Geneva: WHO Framework Convention on Tobacco Control Secretariat, 2012. 